\title{
Three-dimensional tracking of mid-latitude quasi-periodic E-region echoes observed with the Chung-Li VHF radar
}

\author{
C. L. Chen ${ }^{1}$, C. J. Pan ${ }^{1}$, J. Röttger ${ }^{1}$, and V. K. Anandan* \\ ${ }^{1}$ Institute of Space Science, National Central University, Chung-Li, 32054, Taiwan \\ * On leave from National MST Radar Facility, Gadanki, India
}

Received: 13 December 2003 - Revised: 24 October 2004 - Accepted: 31 October 2004 - Published: 28 February 2005

\begin{abstract}
This paper presents observations of low-altitude mid-latitude E-region irregularities obtained with the 52$\mathrm{MHz}$ Chung-Li VHF radar. These are carried out in the interferometer mode to investigate the behavior of these irregularities over time and space. The observations presented here show the characteristics of type-II echoes noted by a negative slope, i.e. they are approaching the radar as a function of time. The range-time-intensity (RTI) plots obtained through power spectrum analysis reveal the quasi-periodic striations, which are known as LQP (Low-altitude QP) echoes. Our interferometer analysis allows one to investigate the motion (i.e. "tracking") of the LQP echo patches in three dimensions. This method is superior to just evaluating the variations of the echo power as a function of range and time in the standard RTI-plots. By applying this method, we show that the echo patches in different striations remain at almost the same altitude when we trace the isolated echoing regions until they disappear from the radar view. We further compare the rate of change of the range (range rate $\mathrm{dR} / \mathrm{dt}$ ) by two techniques: one by simply measuring the varying slope of the LQP echoes from RTI plot, the other by tracking the threedimensional locations of the LQP scatterers by using the interferometer technique. We finally prove that the changes in range as a function of time, deduced from the interferometer technique, are significantly correlated with those of the standard range rate analysis. However, the standard range rate analysis does not provide information about the correct location and the variation of the LQP irregularities. The threedimensional analysis, which we introduced for tracking individual striations, shows that LQP echo patches are confined to between 98 and $100 \mathrm{~km}$ altitude. This suggests that the irregularities which cause the LQP echoes drifted through the radar beam at approximately constant altitude, which we tend to attribute to a region of large-scale vertical shear of the horizontal wind.
\end{abstract}

Key words. Ionosphere (Ionospheric irregularities) - Radio science (Remote sensing; Ionospheric physics; Instruments and techniques)

Correspondence to: C. J. Pan

(cjpan@jupiter.ss.ncu.edu.tw)

\section{Introduction}

Interferometer techniques have been extensively used for the study of ionosphere and atmosphere dynamics. Since Farley et al. (1981) introduced this technique for the study of equatorial electrojet irregularities with the Jicamarca radar, it has been implemented at various VHF radars, such as the MU radar (Yamamoto et al., 1994), the Chung-Li VHF radar (Pan et al., 1994), for instance. The multiple baseline interferometer technique helps to reveal the spatial and temporal characteristics of the scatterers, thereby imaging the motion/tracking of scatterers in the three-dimensional plane (Hysell and Burcham, 2000; Yamamoto et al., 1994; Wang and Chu, 2001). We apply this technique in this paper, as well, and can show that the additional information on the height of the scattering irregularities, creating the LQP echoes, can only be obtained by this more elaborate technique and yields further information about the larger scale behavior of these irregularities. In this paper we are not discussing the scattering mechanism of the irregularities which leads to the LQP echoes. We notice, though, that they are obviously characterized by a high coherence which is consistent with high aspect sensitivity.

The QP echoes at mid-latitudes were first observed with the middle and upper atmosphere (MU) radar in Japan (Yamamoto et al., 1991) and later at other latitudes, as well (Kelley et al., 1995; Pan and Tsunoda, 1998; Hysell and Burcham, 1999; Choudhary and Mahajan, 1999; Chau and Woodman, 1999; Pan and Rao, 2002). The morphology of these echoes was also described by Pan and Rao (2003), who showed that these echoes have different appearances at lower latitudes. Woodman et al. (1991) and later Tsunoda et al. (1994) had explained the generation of these echoes by atmospheric gravity waves modulating the sporadic E-layers $\left(E_{s}\right)$ in such a way so as to make them locally unstable by the gradient drift instability. However, this theory could not fully explain the experimental observations made by sounding rocket campaigns from Japan (Sporadic-E Experiment over Kyushu=SEEK; Fukao et al., 1998; Yamamoto et al., 1998). 


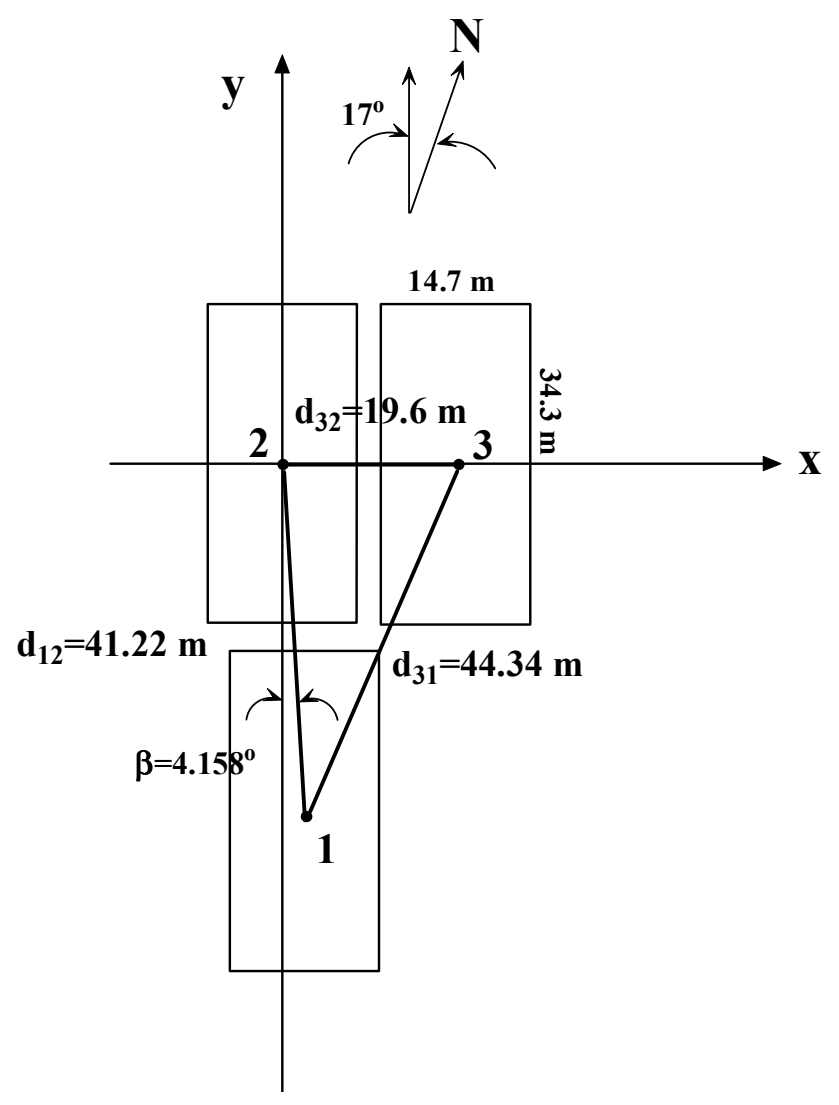

Fig. 1. Geometry of Chung-Li VHF radar antenna array used for interferometer observation. The origin is at the phase center of antenna array 2. The y-axis points toward $17^{\circ}$ west of geocentric north. The phase center of antennas 2 and 3 determine the $\mathrm{x}$-axis, and the $\mathrm{z}$-axis points into the zenith direction.

This theory also failed to explain the observations of multiple striations within the QP echoes (Tsunoda et al., 1999) and their semidiurnal behavior (Pan and Tsunoda, 1999). Recently, Larsen (2000) proposed that neutral wind shear instability can explain the spatial and temporal periodicities associated with QP echoes. It depends on large vertical wind shear of the horizontal wind. Large wind shear at the threshold of instability is frequently observed in connection with $\mathrm{QP}$ echoes. Due to the high collision frequency in this altitude around $100 \mathrm{~km}$, the wind profile reflects itself in the plasma density profile. This then has some kind of similar shear as the neutral wind profile and can give rise to plasma instabilities. This can also explain that the observed plasma striations are assumed to drift with the horizontal wind. Periodicities can be generated by superimposed gravity waves. Haldoupis et al. (2001) studied QP echoes in the zonal direction using azimuth-time-intensity (ATI) analysis. They suggest that these typical striations in mid-latitude E-region backscatter are due to the motion of unstable plasma structures, most likely sporadic-E patches, which drift along with the neutral wind, that have zonal scale lengths of several tens of kilometers, much larger than the size predicted by Larsen's theory. The simulations made by Bernhardt (2002) confirm this as well. More recently, Hysell et al. (2002) used an inbeam radar imaging technique, and applied both refraction and finite aspect angle sensitivity to prove that striations in range-time-intensity (RTI) maps of QP echoes are the signatures of migrations of a spatially localized, elongated scattering region inside a sparsely filled radar volume. Similar observations and conclusions have also been made by Haldoupis et al. (2003). QP echoes are observed simply to be due to sequential unstable plasma patches or blobs which traverse across the radar field-of-view, sometimes in a wave-like fashion. Also, the three-dimensional observations on $30 \mathrm{MHz}$ (Hysell and Burcham, 2000) show that the QP echoes can be recognized as quasi-point target scatterers drifting through the radar beam at approximately constant altitude.

Recently, a striking finding was reported by Rao et al. (2000) by carrying out multi-beam high resolution MU radar observations, Urbina et al. (2000) by simultaneously operating a $50-\mathrm{MHz}$ radar interferometer at Camp Santiago and the Arecibo incoherent scatter radar. Later, the finding was also reported by Pan and Rao (2002) and Patra et al. (2002) by operating at $53 \mathrm{MHz}$ the MST radar located at Gadanki. The new finding of these experiments was that the radar backscatter from lower altitudes $(<100 \mathrm{~km})$ also displays quasi-period features. To differentiate these echoes which have a different appearance at lower altitudes from QP echoes of the kind reported by Yamamoto et al. (1991), low altitude QP (LQP) were adopted for this new class of echoes.

This paper presents interferometry observations carried out using the 52-MHz Chung-Li VHF radar to improve our understanding of the characteristics and behavior of these newly detected low altitude QP echoes, called LQP echoes. We show that the echo patches in different striations remain at almost the same altitude between 98 and $100 \mathrm{~km}$ when we trace the isolated echoing regions until they disappear from the radar view. Then we show that the range variations with time (range rates) along different striations, obtained by two techniques: one by measuring the slope of the LQP echoes from RTI plots, and the other by determining the 3-dimensional locations of the same striations with respect to time by interferometer measurements, are well correlated. In Sect. 2 we describe the observation and the analysis of the experiment. Results and discussion are presented in Sect. 3 and conclusions are drawn in Sect. 4.

\section{Observations and analysis}

The Chung-Li VHF radar (geographic latitude $24.9^{\circ} \mathrm{N}$, $121^{\circ} \mathrm{E}$ ) is a mono-static pulsed Doppler radar operating on 52-MHz. The radar consists of three identical antenna, transmitter and receiver modules, which are coherently phasesynchronized. The geometry of the antenna system used for the interferometry observation is shown in Fig. 1. A further system description of this interferometer mode can be obtained from Pan et al. (1994).

In the period 3-11 July 2000, the radar was operated every night between 18:00 LT and 06:00 LT. The operations 


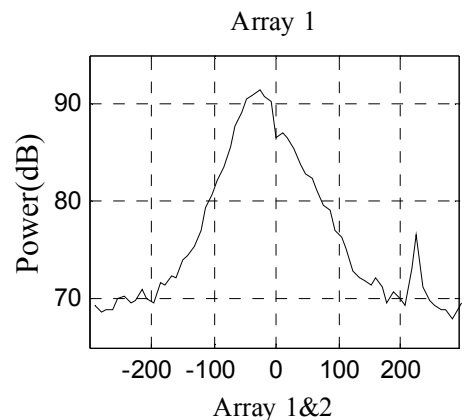

$$
\text { Range }=130.2 \mathrm{~km} \quad \text { LT }=18: 28: 20
$$
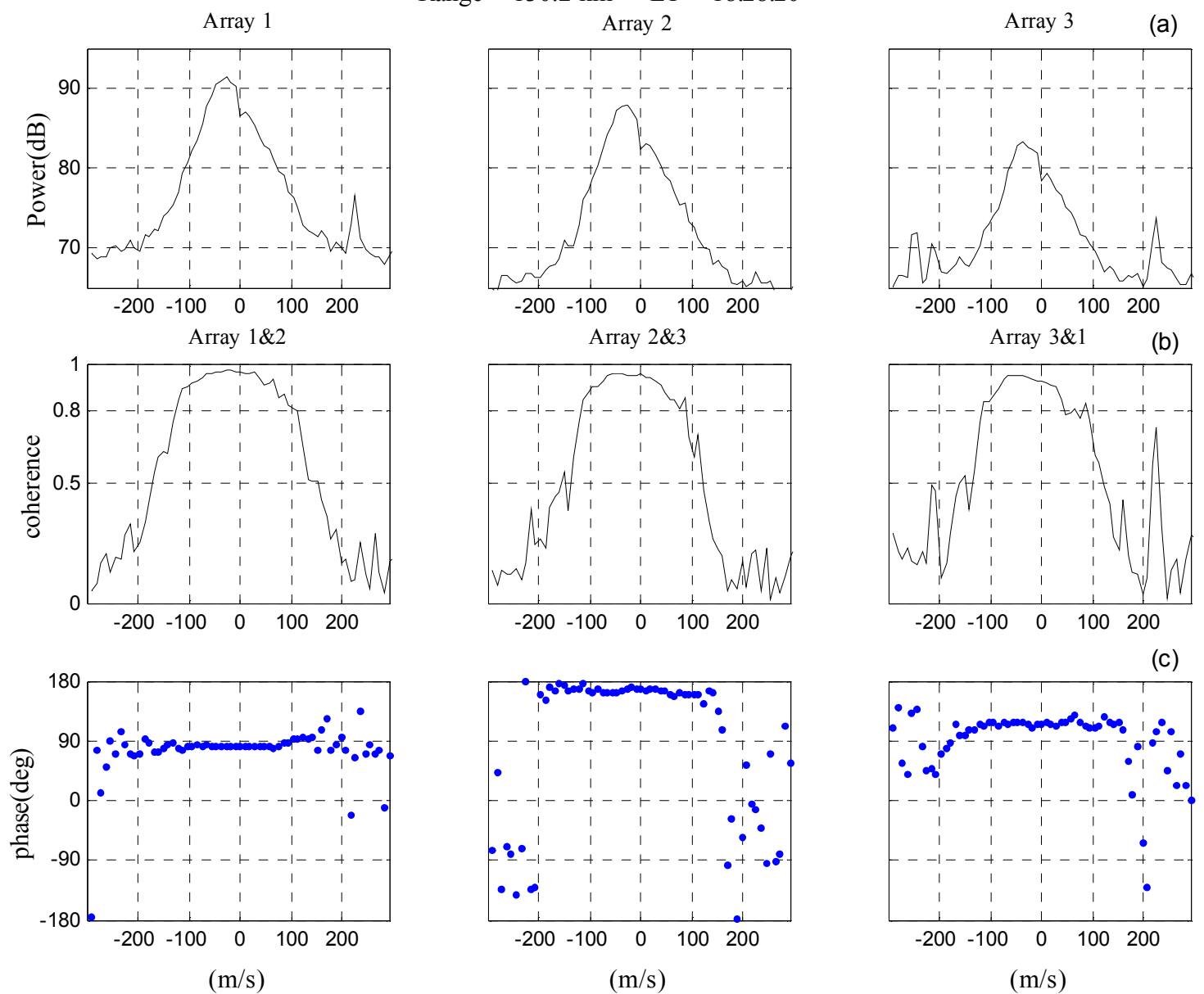

Fig. 2. (a) A sample power spectrum of backscatter signals from $E_{S}$ irregularities received by three antenna arrays observed on 3 July 2000 . (b) Coherence and (c) Phase obtained through cross-spectral analysis for array pairs of 1-2, 2-3, and 3-1 are shown from the left panel to the right panel, respectively.

were done with $4 \mu$ s pulse length ( $600 \mathrm{~m}$ range resolution), an interpulse period of $1200 \mu \mathrm{s}$, coherent integrations over four interpulse periods and with a range observation window of $120 \mathrm{~km}$ to $144 \mathrm{~km}$. A 64-point Fast Fourier Transform (FFT) was used to compute the complex Doppler spectra of the echoes for each range gate of each of the three individual receiving antenna channels. To obtain the rangetime-intensity (RTI) map the complex normalized cross spectrum is computed, is ensemble and averaged over 50 times (around $20 \mathrm{~s}$ ) to obtain the power, coherence and phase. We note that pronounced QP echoes were observed during 18:00 to 20:30 LT on 3 July. We later show with the interferometer method, that these are actually LQP echoes; we note that this feature (namely, LQP) cannot be determined with the standard RTI technique. Figure 2 shows such typical power spectra of echoes observed in the period at the range of $130.2 \mathrm{~km}$ around 18:28 LT. Although pronounced LQP echoes appeared during 18:00 to 20:30 LT, only data with high signal-to-noise ratio from about 18:20 to 18:33 are presented. From the signal power deduced from the spectra we obtain the range-time-intensity diagram shown in Fig. 3.
From the complex Doppler spectra the coherence and the phase as a function of Doppler frequency was calculated for the combinations of the three channels. In order to assure an acceptable significance of the coherence and its phase, a careful noise subtraction of the spectra has been done. A typical case of these spectra is shown in Fig. 2. Following the standard procedure introduced by Farley et al. (1981), these parameters allow for the deduction of the angular spread and the location of the echo targets. The first set of data in Fig. 2 shows typical power with non-zero Doppler shift. The high coherence observed over the total frequency range, where the signal power exceeds a proper limit, supports earlier findings on QP echoes, that the irregularities of these LQP echoes are highly aspect sensitive. Since they are also fairly localized in range, it implies that the signals come, as usual in such cases, from a localized echoing region. If there would not be an aspect sensitivity, we would expect echoes which are not confined to limited ranges but rather spread out.

This is the reasoning behind the characterization of these LQPs to be from localized echoing regions. Further, the phase of the cross spectra would also be random, which we 


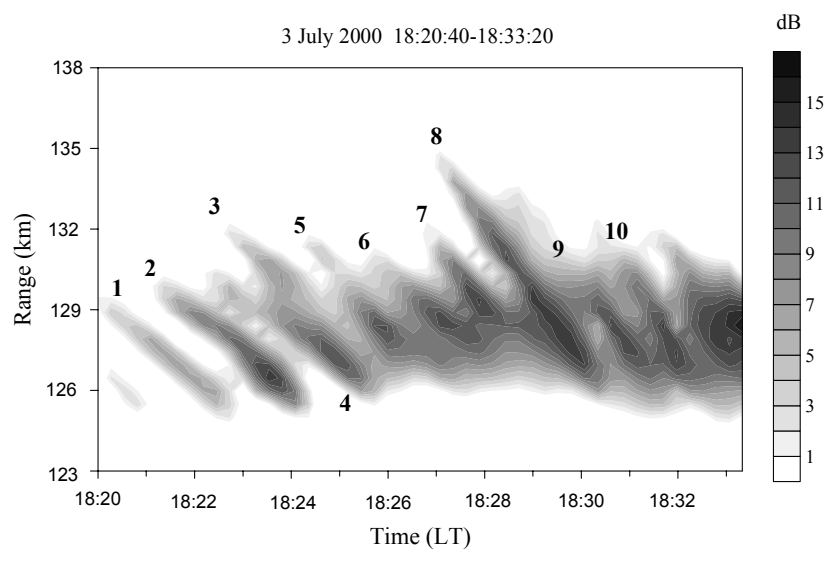

Fig. 3. Range-time-intensity plot of QP echoes observed with the Chung-Li VHF radar between 18:20 to 18:33 LT on 3 July 2000.

do not observe. These observations were typical in our experiment, which means that we can consider the echoes as being from an isolated echoing region in the radar volume.

In order to trace the variation of the location of the echoes, we introduce the following coordinate system: The local zenith direction is the coordinate $\mathrm{z}$ with the origin at the phase center of antenna array 2. Since the antenna beam is pointed in a direction $17^{\circ}$ west of north in azimuth and $49^{\circ}$ in elevation, such that it is perpendicular to the field line at the height of $250 \mathrm{~km}$. However, calculation shows that the elevation angle perpendicular to the field line at the height of $105 \mathrm{~km}$ from the Chung-Li radar site is about $51.5^{\circ}$. We defined the $y$-axis as pointing toward $17^{\circ}$ west of geocentric north, $\mathrm{x}$ is the axis orthogonal to the $\mathrm{y}$ and $\mathrm{z}$ coordinates. From the mean phases of the cross spectra (lower panels of Fig. 2) we deduce the azimuth and elevation of the backscatter locations in each range gate. We have chosen the coherence limit of 0.8 , since here the phase values are very stable and not distorted by noise (see Fig. 2). In order to obtain an reliable arrival angle of the QP echo patches, the phase differences computed from the complex normalized cross spectrum of the echoes for antenna pairs 1-2, 2-3 and 3-1 with coherence exceeding 0.8 were used. From the phase differences $\Delta \phi_{12}(\omega)$ and $\Delta \phi_{23}(\omega)$ for antenna pairs 1-2, 2-3, the elevation angle $\theta(\omega)$ and azimuth angle $\phi(\omega)$ of target can be derived as follows (Wang and Chu, 2001):

$$
\begin{gathered}
\phi(\omega)=\tan ^{-1}\left[\tan \beta+\frac{d_{12}}{d_{23} \cos \beta}\right. \\
\left.\left(\frac{\Delta \phi_{23}(\omega)+2 \pi m+\Delta \Psi_{23}}{\Delta \phi_{12}(\omega)+2 \pi n+\Delta \Psi_{12}}\right)\right]-\beta, \\
\theta(\omega)=\cos ^{-1}\left[\frac{\Delta \phi_{23}(\omega)+2 \pi m+\Delta \Psi_{23}}{k d_{23} \sin \phi}\right],
\end{gathered}
$$

where $\mathrm{k}=2 \pi / \lambda$ is the radar wave number, $\lambda$ is the radar wave length, $\mathrm{m}$ and $\mathrm{n}$ are the interferometry lobe numbers in azimuth and vertical directions, respectively, resulting from grating lobes of this interferometer setup. $\Delta \psi_{12}$ and $\Delta \psi_{23}$
Table 1. Mean projection velocities $(\mathrm{m} / \mathrm{s})$ in the $\mathrm{x}, \mathrm{y}$ and $\mathrm{z}$ directions of the striations in Fig. 3.

\begin{tabular}{llrr}
\hline striation & $\mathrm{dx} / \mathrm{dt}$ & $\mathrm{dy} / \mathrm{dt}$ & $\mathrm{dz} / \mathrm{dt}$ \\
\hline 1 & 15 & -27 & -10 \\
2 & 8 & -29 & -11 \\
3 & 18 & -11 & -10 \\
4 & 8 & -44 & -4 \\
5 & 60 & -37 & -1 \\
6 & 77 & -38 & 0 \\
7 & 122 & -44 & -1 \\
8 & 68 & -23 & -7 \\
9 & 127 & -70 & 6 \\
10 & 152 & -72 & 1 \\
\hline
\end{tabular}

represent the system phase biases for antenna pairs 1-2 and $2-3$, respectively, and $\beta$ is the angular deviation between antenna pairs from the right angle triangle, as shown in Fig. 1. To determine the values of $\mathrm{m}$ and $\mathrm{n}$, the angular range in which all-possible Es echoes may appear has to be considered. Using the IGRF-2000 model these angular ranges were estimated. The values $\mathrm{n}=4, \mathrm{~m}=0,-1, \Delta \psi_{12}=295^{\circ}$ and $\Delta \psi_{23}=5^{\circ}$ in Wang and Chu (2001) are used for our estimation. Using Eqs. (1) and (2), the coordinates of the target in different gate $R$ is obtained from

$$
\begin{aligned}
& x(\omega)=R \cos \theta(\omega) \sin \phi(\omega), y(\omega) \\
& =R \cos \theta(\omega) \cos \phi(\omega) \text { and } z(\omega)=R \sin \theta(\omega) .
\end{aligned}
$$

When we trace the striations in the RTI plot and compared the related gate and time with the data obtained by interferometry, we obtain the positions of LQP echo patches in different striations, respectively. To obtain the mean velocity projections in the $\mathrm{x}, \mathrm{y}$ and $\mathrm{z}$ directions of the striations, we need the mean locations of the scattering patches in every gate. We have averaged the $\mathrm{x}, \mathrm{y}$ and $\mathrm{z}$ obtained from Eq. (3) for all Doppler frequencies with coherence larger than 0.8, respectively. The mean projection velocities in the $\mathrm{x}, \mathrm{y}$ and $\mathrm{z}$ directions of different striations are shown in Table 1.

\section{Results and discussion}

As the RTI plot in Fig. 3 shows, there are multiple echo traces which comprise QP echoes with up to four striations being visible at the same time (around 18:27 LT). There are reports on the simultaneous presence of multiple of QP echoes with up to 8 to 9 striations (Tsunoda et al., 1999; Hysell and Burcham, 2000). From our observations it is apparent that the echo patches inside the striations were varying with time and have negative slope, which means that they propagated towards the radar.

Since the interferometer data as a function of range provide more detailed information on the spatial structure of the irregularities representing the LQP echoes, we can derive the 

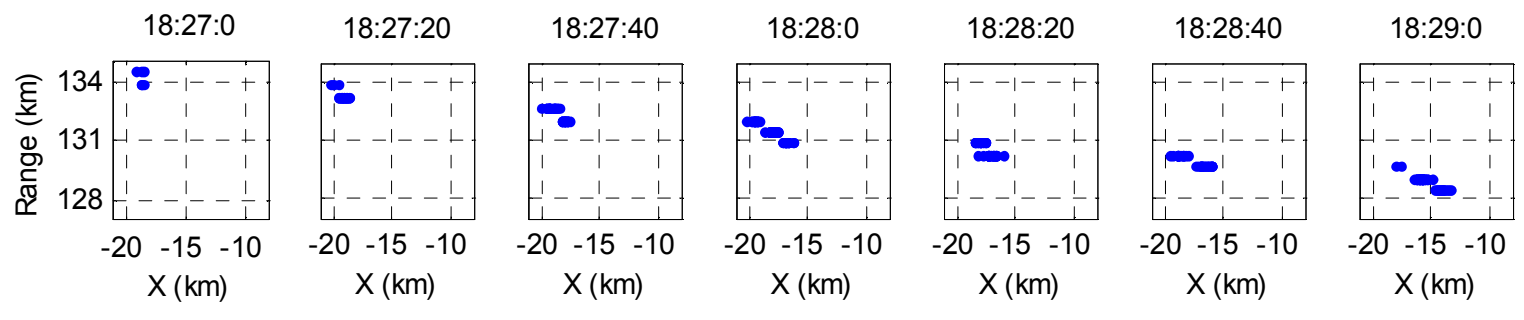

18:29:20
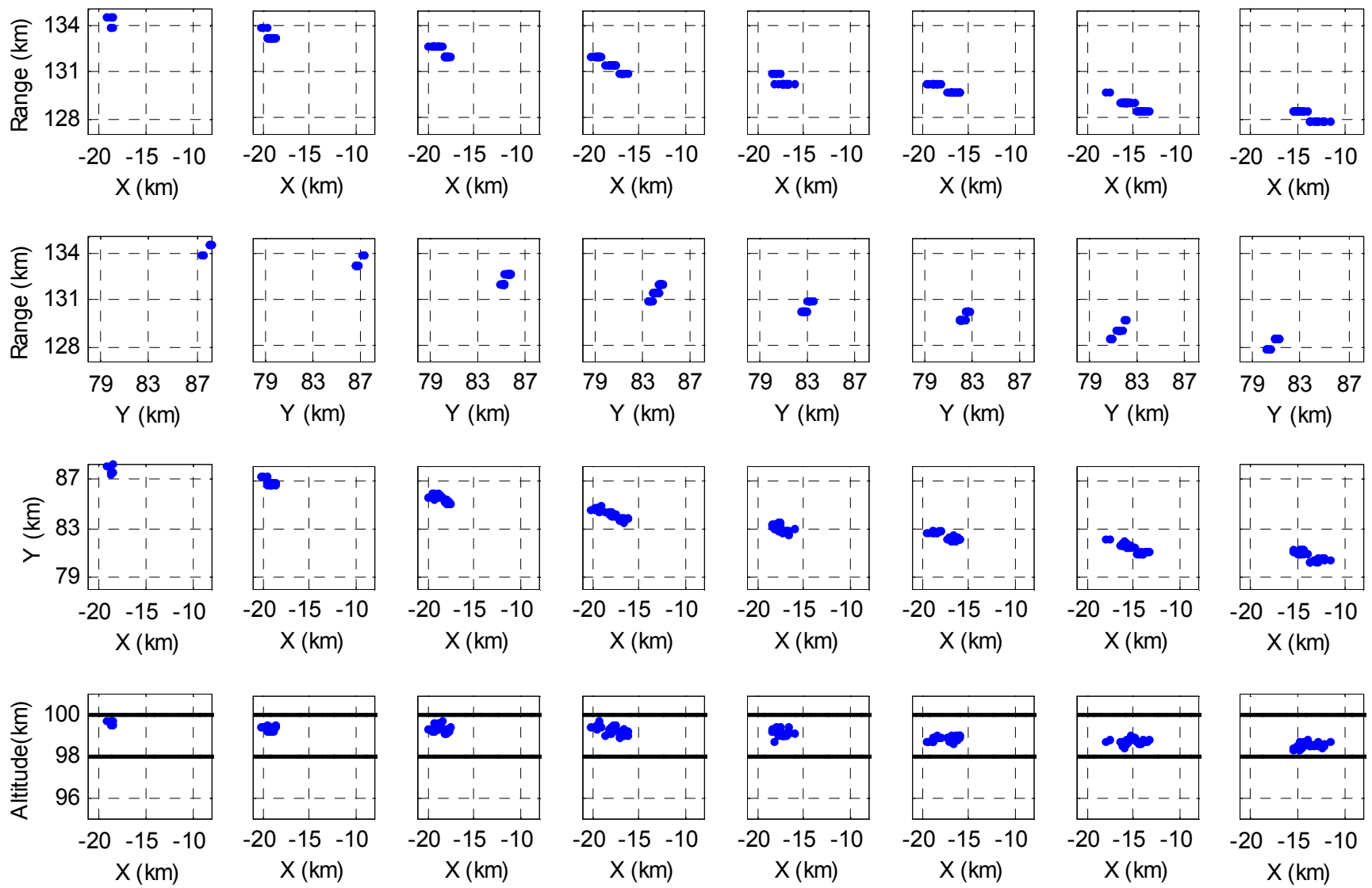

Fig. 4. Series of three-dimensional distribution of the striation number 8 (Fig. 3) of the QP echoes, observed by the interferometry technique. The data start at 18:27:00 and end at 18:29:20 LT on 3 July 2000. The first two panels display the range vs. the x- and y- axes, respectively. The third panels display the motion projected in the $\mathrm{x}-\mathrm{y}$ plane. The bottom panel shows the altitude vs. the $\mathrm{x}$-axis.

three-dimensional location of the backscatter in each range gate and the time history about the spatial variation of the LQP echoes as well.

The combination of the three-dimensional variations of the isolated echoing region along with RTI plots and velocity measurements is important to infer the dynamics of the $E_{s}$ irregularities causing the LQP echoes. It is interesting to investigate whether these irregularities are being created in-situ (i.e. by movement of an instable background), or exist and are advected with the background (i.e. move into the radar observing volume). This is not an unambiguous task, but our observations and interpretations seem to provide a tool for this purpose.

Figure 4 presents a representative example of the motion of the eighth striation patch (see Fig. 3 for numbering). When we trace the eighth striation in the RTI plot and compared the corresponding gate and time with the data obtained by interferometry, we obtain the positions of patches obtained from Eq. (3) and displayed for all Doppler frequencies with coherences of more than 0.8 . The first two panels display the range vs. the $\mathrm{x}-$ and $\mathrm{y}$ - axes, respectively. The third panel displays the motion projected in the $x-y$ plane. The bottom panel shows the altitude vs. the $\mathrm{x}$-axis. The time increases from the left column to the right column. Its range distribution is from $134 \mathrm{~km}$ down to $126 \mathrm{~km}$, which is an extent of about 8 to $9 \mathrm{~km}$. Comparing the data obtained by interferometry with the IGRF 2000 model, we find the corresponding angular range with respect to the Earth's magnetic field producing the LQP echoes mainly within $\pm 0.5^{\circ}$ and no more than $\pm 1^{\circ}$ off the perpendicularity direction to the Earth's magnetic field. When we traced the striation 8 , the echo patches drift into the radar volume and disappear from the radar view; meanwhile, the aspect angular range shifts from negative (about $-0.5^{\circ}$ ) to positive (about $0.5^{\circ}$ ). This is well consistent with a very localized, point-like scattering region responsible for the LPQ echoes. Viewing the sequences of the columns (corresponding to time variation) reveals that the echo patches with zonal extents of about 2 to $6 \mathrm{~km}$ drifted towards southeast and resided at altitudes between $98 \mathrm{~km}$ and $100 \mathrm{~km}$. The echo patches are confined to a narrow altitude and are nearly field-aligned. The zonal extent of the echo patches along the striation 8 is extended for a moment and then decreased before the echo patches vanished. From these features, it also follows that the isolated echoing region was embedded in a very spatially localized region in the radar volume. 


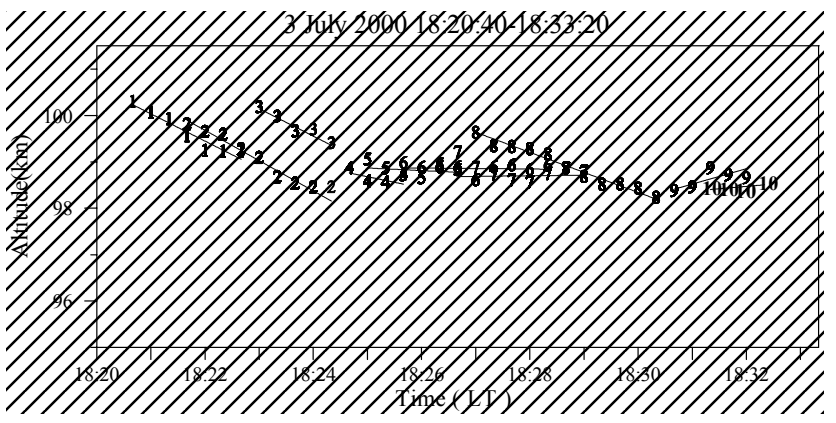

Fig. 5. Averaged altitude variations of ten striations during their existence in the radar volume on 3 July 2000.

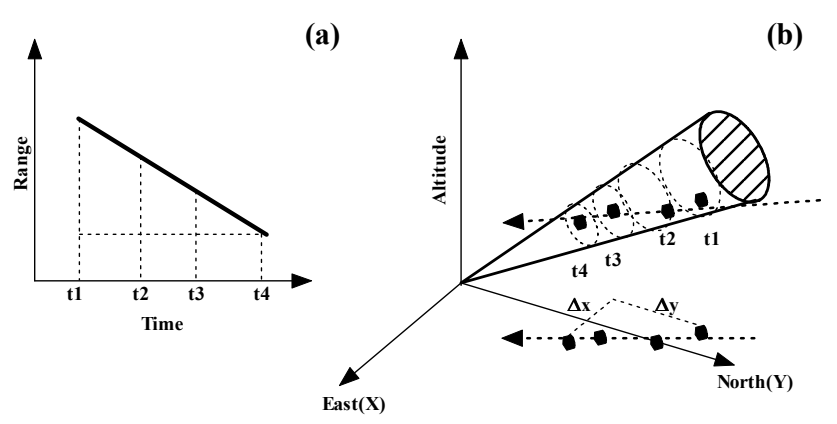

Fig. 6. (a) A sketch of an ideal striation in the range time plot. (b) Simple geometry of an ideal striation by tracing an isolated echoing region with a constant velocity at a fixed altitude, which would result in the range-time variation in (a).

Similar characteristics are observed in all striations of our LQP echoes, which we detected. In order to show more clearly the altitude behavior of the LQP echoes, ten striations were plotted together in Fig. 5. From Fig. 5, it seems to indicate that the irregularities drift into the radar volume and they stay in the same altitude between $98 \mathrm{~km}$ and $100 \mathrm{~km}$ before 18:40 LT. After this period, they stay in the altitude between $95 \mathrm{~km}$ and $98 \mathrm{~km}$ until they disappear from the radar view. Around 18:27 LT, there are four striations coexisting in different range gates in the RTI plot (Fig. 3). But Fig. 5 reveals that they stay at almost the same altitude. Let us presume that it is most unlikely that they were associated with different sporadic-E layer. Similar to the projection in the $\mathrm{x}$ y plane of the striation 8 in Fig. 4, we find that they simply change their locations only in the $\mathrm{x}-\mathrm{y}$ plane, i.e. they move horizontally.

From the results described above we propose an interpretation of the striations of these LQP echoes, as they presumably can be characterized as isolated echoing regions, which drift at constant altitude and with fairly constant horizontal velocity through the radar observing volume. Figure $6 a$ diagrams a drifting echo patch (single striation) as it is viewed in the backscattered radar signal. Figure $6 \mathrm{~b}$ shows the threedimensional view of the echo patches as a function of time.

Based on these observations, a numerical simulation is suggested for obtaining the range rate (i.e. the change of range as a function of time deduced from the RTI plot) of

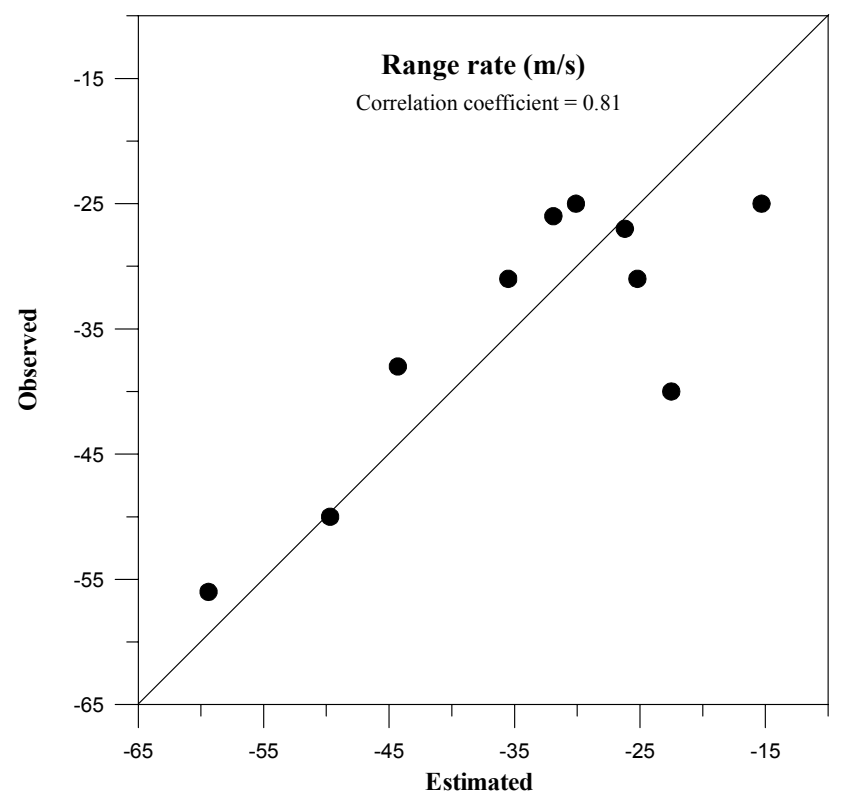

Fig. 7. Correlation of the range rates $\mathrm{dR} / \mathrm{dt}$ obtained by two observing methods. The ordinate displays the range rate deduced from the RTI plot (Fig. 3), and the abscissa displays the range rate estimated from Eq. (4) by the interferometry technique.

the echoes when they drift into the radar volume. Take the coordinates of the target as $\mathrm{P}(\mathrm{x}, \mathrm{y}, \mathrm{z})$, which moves with velocity

$U=\left(\frac{d x}{d t}, \frac{d y}{d t}, \frac{d z}{d t}\right)$ at the range $R=\sqrt{x^{2}+y^{2}+z^{2}}$,

where $x=R \cos \theta \sin \phi, y=R \cos \theta \cos \phi$ and $z=R \sin \theta, \theta$ and $\phi$ are elevation and azimuth angles, respectively. Then we obtain the range rate,

$\frac{d R}{d t}=\cos \theta \sin \phi \frac{d x}{d t}+\cos \theta \cos \phi \frac{d y}{d t}+\sin \theta \frac{d z}{d t}$,

where $d x / d t, d y / d t$ and $d z / d t$ are the velocity projections of the target in the $\mathrm{x}, \mathrm{y}$ and $\mathrm{z}$ direction, respectively. The mean velocity projections in the $\mathrm{x}, \mathrm{y}$ and $\mathrm{z}$ directions of the striations are used for our $d x / d t, d y / d t$ and $d z / d t$, respectively. Using Eqs. (1) and (2), we find that the elevation and azimuth of the targets lay between $48^{\circ} \leq \theta \leq 53^{\circ},-15^{\circ} \leq \phi \leq 5^{\circ}$, respectively. By finding $\theta(\omega)$ and $\phi(\omega)$ for individual echo patches and mean velocity projections in the $\mathrm{x}, \mathrm{y}$ and $\mathrm{z}$ directions of the striation, the range rate is estimated and averaged, respectively. In order to qualify this estimate, deduced from the interferometer measurements, we compared these results with the observed range rate, which is obtained from the slope of the striations in RTI plot. Figure 7 presents the corresponding correlation of the range rate deduced directly from the RTI and the one deduced from the interferometer measurements.

The result shows very good agreement of these values deduced by the two independent techniques. The mean ratios of range rates, deduced from the interferometer, and the range 
rates obtained from RTI plot are between 0.8 and 1.2, except for striations 3 and 8 , with about 0.6 . This result suggests that the magnitudes of the range rates obtained from interferometry method are close to those which we obtained from the RTI plot. The correlation coefficient up to 0.8 ensures that our conclusion has a good statistical significance.

In general, it is widely reported that $\mathrm{QP}$ echoes occur at higher altitudes $(>100 \mathrm{~km})$ than we observed here. Recently, the radar backscatter from low altitudes where the "continuous" echoes usually appear also displayed quasi-periodic features. To distinguish these echoes from QP echoes of the kind reported by Yamamoto et al. (1991), the name "Low altitude QP" (LQP) was adopted for this class of echoes and we have shown here that they really are at low altitudes and also remain at about the same mean altitude during the observing period of several tens of minutes.

In summary, a significant difference between these two types of echoes is that the LQP echoes are confined to a narrow height band of about 2-4 km, whereas the QP echoes often extend for more than $20 \mathrm{~km}$ above $100 \mathrm{~km}$ altitude (Pan and Rao, 2002). The altitude observed in this experiment is below $100 \mathrm{~km}$ and extends no more than $4 \mathrm{~km}$ with periodicity around $2 \mathrm{~min}$, which seem to resemble the features of LQP echoes.

Chu and Wang (1997), by using the interferometry technique, showed that the QP echoes in the RTI plot can result from the isolated and discrete plasma irregularities drifting in the illuminating region at a constant speed along a fixed and stationary track. Those QP echoes occur mainly above the range of $140 \mathrm{~km}$, whose corresponding height is above $110 \mathrm{~km}$. The striation spacing in the range is about $8-15 \mathrm{~km}$. In the RTI plot they show positive slopes, with a range rate at about $48 \mathrm{~m} / \mathrm{s}$, and the lifetime of each streak within 5$10 \mathrm{~min}$. On the other hand, our observation shows features of LQP echoes which is the first time reported study with the Chung-Li VHF radar.

Striations in the RTI plots could be interpreted in several ways. The slope of the striation in the RTI plot shows that the patches move toward the radar or away from the radar depending on whether the slope is negative or positive. One interpretation is in terms of tracing the isolated echoing regions that drifted into the radar volume. If so, then the range rates of the QP echoes are mainly indicative of the radial drift of the scatters. By two different techniques of calculating the range rate, the agreement between the range rates in the RTI plots and the estimated range rates from interferometry supports our conjecture that LQP echoes behave like spatially localized scatters. The elevation and azimuth of observed data lay between $48^{\circ} \leq \theta \leq 53^{\circ},-15^{\circ} \leq \phi \leq 5^{\circ}$, respectively. The estimated values are about $|\cos \theta \sin \phi|<0.2,0.57<\cos \theta$ $\cos \phi<0.67$, and $\sin \theta<0.8$, respectively. Although sometimes the zonal components of the deduced trace velocities is $150 \mathrm{~m} / \mathrm{s}$, the contributions to the range rate slope of LQP echoes are mainly resulting in the meridional drift of the scattering irregularity regions.

At one time, a high multiplicity of QP echoes has been observed (Tsunoda et al., 1999; Hysell and Burcham, 2000).
It is unlikely that multiple striations can be associated with distinct sporadic E-layers. The finding of LQP echo patches in multiple striations being at a constant height could clarify that the striations can be interpreted as the signatures of an isolated echoing region drifting horizontally at about constant altitude. If there were several isolated patches staying in the radar volume and they were distributed in different range gates, respectively, then they would drift for a time and vanished, respectively. The counterpart in the RTI plot is multiple striations of LQP echoes with different range rates, depending on their speeds away from or toward the radar. Because of their patchy appearance, and since they are associated with an isolated echoing region traversing across the radar beam, the echoes seem to inherently bear a degree of quasi-periodic character. The striation periodicity behaves diversely. It is related to the space between isolated patches drifting into the radar volume.

It is most likely that the original wind shear remains at about the same altitude over the fairly short distance in which we observe these echoes. The height around $100 \mathrm{~km}$ is a wind shear preferential altitude (Larsen, 2000). When we reasonably assume that the observed LQP echoes are in a wind shear, the wind shear only changes with altitude and slowly with time. Since patches embedded in the background wind likely move at the velocity of the mean wind or the plasma drift within the unstable shear region, a change in the sign of the range rate should reflect a reversal in the neutral wind velocity component toward or away from the radar, i.e. in the meridional wind direction.

Our results on the general nature of these LQP echoes could be interpreted in the following way: Since the irregularity patches remain at about constant height, we assume that they are generated in a strong shear region, which extends over a large horizontal distance at constant altitude. The patches generated by the wind instability, in turn, cause the quasi-periodic striations when they drifted into radar volume. The RTI striations of LQP echoes are then the signatures of migration of spatially localized and unstable plasma structures or a gradient wind field. Given a reversal in the neutral wind or plasma velocity components, the striations should reflect a slope change in the RTI plot. When there are several patches coexisting in the radar volume, we find multiple striations at one time. In order to discriminate between the neutral and plasma instability mechanisms responsible for these striations, measurements of neutral wind profiles are need, which our experiments cannot provide. We propose that this may be done in a campaign applying a combination of different instruments.

\section{Summary}

The presented studies of the variation of the LQP echo, i.e. those echoes from altitudes of less than $100 \mathrm{~km}$, when we traced the isolated patchy or striated radar targets in three dimensions, show that the scattering irregularities in the LQP echoes remain at approximately a constant altitude. These 
irregularities drift into and through the radar beam at around $98 \mathrm{~km}$ to $100 \mathrm{~km}$ altitudes. The study also reveals that, in the same time period, echo patches in different QP echo striations did exist at the same altitude. It is shown that the dynamics of the LQP irregularities, i.e. their motion, can significantly be obtained from the combination of the rangetime-intensity and the interferometer techniques using VHF radar. The application of the latter, namely the interferometer method, is mandatory to determine the proper threedimensional behavior of these LQP echoes, namely to show that they are really at low altitudes. We also found that they kept their altitude during the observing time and that the range rate changes are essentially only caused by the change in horizontal position.

Acknowledgements. The authors were supported by the National Science Council of the Taiwan/R.O.C. through the grant NSC 912811-M008-0025 during the course of the study described here.

Topical Editor M. Lester thanks two referees for their help in evaluating this paper.

\section{References}

Bernhardt, P. A.: The modulation of sporadic-E layers by KelvinHelmholtz billows in the neutral atmosphere, J. Atmos. Sol-Terr. Phys., 64, 1487-1504, 2002.

Chau, J. L. and Woodman, R. F.: Low-latitude quasiperiodic echoes observed with the Piura VHF radar in the E-region, Geophys. Res. Lett., 26, 2167-2170, 1999.

Choudhary, R. K. and Mahajan, K. K.: Tropical E-region fieldaligned irregularities: Simultaneous observations of continuous and QP echoes, J. Geophys. Res., 104, 2613-2619, 1999.

Chu, Y. H. and Wang, C. Y.: Interferometry observations of threedimensional spatial structures of sporadic-E irregularities using the Chung-Li VHF radar, Radio Sci., 32, 817-832, 1997.

Farley, D. T., Ierkic, H. M., and Fejer, B. G.: Radar interferometry: a new technique for studying plasma turbulence in the ionosphere, J. Geophys. Res., 86, 1467-1472, 1981.

Fukao, S., Yamamoto, M., Tsunoda, R. T., Hayakawa, H., and Mukai, T.: The SEEK (Sporadic-E Experiment over Kyushu) campaign, Geophys. Res. Lett., 25, 1761-1764, 1998.

Haldoupis, C., Hussey, G. C., Bourdillon, A., and Delloue, J.: Azimuth-Time-Intensity striations of quasiperiodic radar echoes from the mid-latitude E-region ionosphere, Geophys. Res. Lett., 28, 1933-1936, 2001.

Haldoupis, C., Bourdillon, A., Kamburelis, A., Hussey, G. C., and Koehler, J. A.: $50 \mathrm{MHz}$ continuous wave interferometer observations of the unstable mid-latitude E-region ionosphere, Ann. Geophys., 21, 1589-1600, 2003,

\section{SRef-ID: 1432-0576/ag/2003-21-1589.}

Hysell, D. L. and Burcham, J. D.: HF radar observations of quasiperiodic $E$ - layer echoes over North America, J. Geophys. Res., 104, 4361-4371, 1999.

Hysell, D. L. and Burcham, J. D.: The 30-MHz radar interferometer studies of midlatitude E-region irregularities, J. Geophys. Res., 105, 12 797-12 812, 2000.

Hysell, D. L., Yamamoto, M., and Fukao, S.: Imaging radar observations and theory of type I and type II quasiperiodic echoes, J. Geophys. Res., 107, doi10.1029/2002JA009292, 2002.
Kelly, M. C., Riggin, D., Pfaff, R. F., Swartz, W. E., Providakes, J. F., and Huang, C. S.: Large amplitude quasi periodic fluctuations associated with a midlatitude sporadic-E layer, J. Atmos. Terr. Phys., 57, 1165-1178, 1995.

Larsen, M. F.: A shear instability seeding mechanism for quasiperiodic radar echoes, J. Geophys. Res., 105, 24 931-24 940, 2000.

Pan, C. J., Liu, C. H., Röttger, J., and Su, S. Y.: A three dimensional study of E-region irregularity patches in the equatorial anomaly region using the Chung-Li VHF radar, Geophys. Res. Lett., 21, 1763-1766, 1994.

Pan, C. J. and Tsunoda, R. T.: Quasi-periodic echoes observed with the Chung-Li VHF radar during the SEEK campaign, Geophys. Res. Lett., 25, 1809-1812, 1998.

Pan, C. J. and Tsunoda, R. T.: Semidiurnal behavior of quasiperiodic echoes in the mid-latitudes Es region observed with the Chung-Li VHF radar, Geophys. Res. Lett., 26, 2621-2624, 1999.

Pan, C. J. and Rao, P. B.: Low altitude quasi-periodic radar echoes observed by the Gadanki VHF radar, Geophys. Res. Lett., 29 (10), doi10.1029/2001GL014331, 2002.

Pan, C. J. and Rao, P. B.: Morphology of the field-aligned E-layer irregularities observed by the Gadanki VHF radar, Proceedings of the Tenth workshop on technical and scientific aspects of MST radar 13-20 May 2003, Piura, Peru, 114-117, 2003.

Patra, A. K., Sripathi, S., Kumar, V. S., and Rao, P. B.: Evidence of kilometer-scale waves in the lower E-region from high resolution VHF radar observations over Gadanki, Geophys. Res. Lett., 29 (10), doi1029/2001GL013340, 2002.

Rao, P. B., Yamamoto, M., Uchida, A., Hassenpflug, I., and Fukao, S.: MU radar observations of kilometer-scale waves in the midlatitude lower E-region, Geophys. Res. Lett., 27, 3667-3670, 2000.

Tsunoda, R. T., Fukao, S., and Yamamoto, M.: On the origin of quasi-periodic radar backscatter from midlatitude sporadic-E, Radio Sci., 29, 349-365, 1994.

Tsunoda, R. T., Buoncore, J. J., Saito, A., Kishimoto, T., Fukao, S., and Yamamoto, M.: First observations of quasi-periodic radar echoes from Stanford, California, Geophys. Res. Lett., 26, 995998, 1999.

Urbina, J., Kudeki E., Franke, S. J., Gonzalez, S., Zhou, Q., and Collins, S. C.: $50 \mathrm{MHz}$ radar observations of mid-latitude Eregion irregularities at Camp Santiago, Puerto Rico, Geophys. Res. Lett., 27, 2853-2856, 2000.

Wang, C. Y. and Chu, Y. H.: Interferometry investigations of bloblike sporadic-E plasma irregularity using the Chung-Li VHF radar, J. Atmos. Solar-Terr. Phys., 63, 123-133, 2001.

Woodman, R. T., Yamamoto, M., and Fukao, S.: Gravity wave modulation of gradient drift instabilities in mid-latitude sporadic- $E$ irregularities, Geophys. Res. Lett., 18, 1197-1200, 1991.

Yamamoto, M., Fukao, S., Woodman, R. F., Ogawa, T., Tsuda, T., and Kato, S.: Midlatitude E-region field-aligned irregularities observed with the MU radar, J. Geophys. Res.,96, 15 943-15 949, 1991.

Yamamoto, M., Komoda, N., Fukao, S., Tsunoda, R. T., and Ogawa, T.: Spatial structure of the E-region field aligned irregularities revealed by the MU radar, Radio Sci., 29, 337-347, 1994.

Yamamoto, M., Ono, T., Oya, H., Tsunoda, R.T., Larsen, M. F., Fukao, S., and Yamamoto, M.: Structure in sporadic- $E$ observed with an impedance probe during the SEEK campaign: Comparisons with neutral-wind and radar-echo observations, Geophys. Res. Lett., 25, 1781-1784, 1998. 